http://dx.doi.org/10.5902/223611708226

REGEJAFSM

Revista do Centro do Ciências Naturais e Exatas - UFSM, Santa Maria

Revista Eletronica em Gestão, Educação e Tecnologia Ambiental - REGET

e-ISSN 22361170 - v. 12 n. 12 jul. 2013, p. 2568 - 2576

\title{
Mestrado profissionalizante e novas tecnologias educacionais: uma proposta de ambiente virtual de ensino e aprendizagem
}

Professional vocational master's degree and as new educational technologies: a proposal for an online teaching and learning environment

\section{Marcelo Barcellos da Rosa'}

IProfessor Adjunto - Departamento de Química da Universidade Federal de Santa Maria

\section{Resumo}

O mestrado profissionalizante em Tecnologia Mineral da Universidade Federal do Pampa, em parceria com a Universidade Federal do Rio Grande do Sul e Universidade Federal de Santa Maria foi recomendado pela CAPES em meados de 2012 e tem seu início previsto para o primeiro semestre de 2013. Este artigo apresenta uma proposta da utilização de um ambiente virtual de ensino e aprendizagem para três disciplinas, Ciclos Biogeoquímicos, Fundamentos da Ecotoxicologia e Controle Ambiental da Água, utilizando a plataforma Moodle e visando atender como modelo aos docentes e ser aplicável aos discentes. As características semipresenciais do curso, assim como a heterogeneidade da clientela justificam a aplicação de tecnologias alternativas na consolidação do curso. Portanto, a proposta se apresenta como uma forma diversificada de ensino, uma vez que disponibiliza diversas ferramentas, entre elas, blogs, e-mails, fóruns, chats, galerias, diários e materiais atualizados (vídeos, textos) que contribuem para a fixação dos módulos trabalhados presencialmente. Assim, esta proposta permitirá uma interação entre os usuários quanto a exposição de sua opinião, contribuindo para o debate e troca de informações, além de oferecer tanto a possibilidade de aprendizagem de forma assíncrona ou síncrona, quanto de gestão do tempo e local para o estudo, ou seja, flexibilidade.

Palavras Chave: mestrado profissional, novas tecnologias educacionais, Moodle.

\begin{abstract}
The professional master's degree in Mineral Technology of the Federal University of Pampa, in partnership with the Federal University of Rio Grande do Sul and Federal University of Santa Maria was recommended by CAPES in mid-2012 and has its beginning scheduled for the first semester of 2013. In this paper, a proposal for a virtual media for teaching and learning for three disciplines, biogeochemical cycles, fundamentals of ecotoxicology and environmental control of water, using the Moodle platform aim to use the program as a model to be applicable to professors and master students, is presented. The characteristics semipresential of the course, as well as the heterogeneity of the students justify the application of alternative technologies in the consolidation of the course. Therefore, the proposal is presented as a diversified manner, as it provides a variety of various tools, including blogs, emails, forums, chat rooms, galleries, and daily updated materials (videos, texts) that contribute to the setting of modules worked in person. Thus, this proposal will allow an interaction between the users and the exposure of your opinion and contributing to the discussion and exchange of information, and provides both the possibility of learning asynchronously or synchronously, as well management time and location for the study, ie flexibility.
\end{abstract}

Keywords: professional master, new educational technologies, Moodle. 


\section{INTRODUÇÃO}

\section{Mestrado Profissionalizante no Brasil}

De acordo com documento expedido pela CAPES, após reunião do seu comitê técnico científico, em setembro de 1999 (CAPES, 1999),

A criação do Mestrado Profissionalizante responde a uma necessidade socialmente definida de capacitação profissional de natureza diferente da propiciada pelo Mestrado Acadêmico e não se contrapõe, sob nenhum ponto de vista, à oferta e expansão desta modalidade de curso, nem se constitui em uma alternativa para a formação de mestres segundo padrões de exigências mais simples ou menos rigorosos do que aqueles tradicionalmente adotados pela pós-graduação brasileira

e ainda,

com a oferta do Mestrado Profissionalizante, o Sistema Nacional de Pós-graduação amplia sua interface com os setores não acadêmicos da sociedade brasileira e passa a se voltar também para a formação de mestres para o exercício de profissões outras que não a de docente pesquisador.

Portanto, o mestrado profissional é voltado para profissionais que querem avançar seus conhecimentos, sejam funcionários de empresas, sejam professores. Ou seja, é um mestrado para quem trabalha em período integral e não tem disponibilidade de tempo para se dedicar a uma proposta acadêmica (Barros et al., 2005; Silveira e Pinto, 2005; Ribeiro, 2006).

\section{Novas tecnologias}

Mudar a forma tradicional de ensino é um desafio, pois envolve a quebra de paradigmas culturais. Introduzir novas metodologias e tecnologias no processo de ensino-aprendizagem requer investimento, tanto em equipamentos e infraestrutura, quanto em capacitação dos professores. Anjos e Andrade, com base em Pierre Levy, destacam que:

A mudança constante do saber, na forma de informação, no âmbito da rede, demonstra a força comunicativa do ciberespaço (Internet). Na medida que a internet se propaga pelo globo, em especial na instituição de ensino, a capacidade de inteligência coletiva aumenta, porque na troca de informações entre indivíduos de diferentes etnias ocorre, incondicionalmente, uma ampliação interpretativa sobre um tema em comum. (Andrade e Anjos, 2008, p. 9).
As tecnologias da informação e comunicação (TIC) estão a cada dia se consolidando mais e mais. O computador tornou-se uma ferramenta essencial e a academia já tomou consciência de que é através das TIC que os mestrandos se comunicam com o mundo. Com a internet, diversas ferramentas de comunicação foram desenvolvidas e inúmeros recursos agregados e hoje possível acessar um espectro inesgotável de informação que nos permite uma comunicação direta e em tempo real com todo o mundo. As TIC podem ser utilizadas na educação em contextos muito diversificados, com objetivos e formas de exploração também muito distintas. A situação mais comum é a sua utilização em atividades não presenciais como suporte às atividades de ensino, como é o caso das apresentações eletrônicas para suporte à exposição do professor na apresentação de conteúdos ou acesso em sala de aula a recursos disponíveis na internet.

A progressiva expansão da Internet e do www, o surgimento de software de fácil utilização capaz de criar e editar páginas para a web, bem como a expansão de serviços de comunicação como o correio eletrônico, fóruns, chats e videoconferência, vieram permitir novas formas de comunicação à serviço dos diversos setores da comunidade educativa e sua relação com a sociedade. (Levy, 1997; Belloni, 1999; Primo, 2001; Silva, 2003; Silva Jr., 2003; Haguenauer et al., 2007; Paiva, 2010).

\section{Plataforma Moodle}

O Moodle (Modular Object Oriented Distance Learning) é um sistema de gerenciamento que permite criação ambientes virtuais de aprendizagem. É um software livre de apoio à aprendizagem e pode ser instalado em várias plataformas tais como Unix, Linux, Windows e MAC OS. Como base de dados podem ser utilizados MySQL, PostgreSQL, Oracle, Access, Interbase ou ODBC. A plataforma vem sendo utilizada não só como ambiente de suporte à Educação a Distância, mas também como apoio a cursos presenciais, semipresenciais, formação de grupos de estudo e treinamento de professores. (Lopez et al., 2010)

Esse software oferece uma estrutura administrativa (dados cadastrais, relatório, lista de presença, calendário), acadêmica (dicas, pesquisa, disciplinas, glossário, roteiros de estudo), bem como ferramentas de interação (e-mail, chat, wiki e fórum), possibilitando uma ampla gama de canais de comunicação entre os participantes, que podem ser selecionadas pelo professor, de acordo com 
Tabela 1 . Vantagens e desvantagens do Moodle.

\begin{tabular}{|c|c|}
\hline Vantagens & Desvantagens \\
\hline $\begin{array}{l}\text { É diversificada; disponibiliza diversas } \\
\text { ferramentas (blog, e-mail, fórum, chat, galeria, } \\
\text { diário, etc.) e materiais atualizados (vídeos, } \\
\text { textos) que contribuem para a aprendizagem; é } \\
\text { de fácil utilização por parte dos pós-graduandos; } \\
\text { permite a interação entre os usuários e a } \\
\text { exposição de sua opinião, contribuindo para o } \\
\text { debate e troca de informações; permite } \\
\text { alterações dos arquivos gerados; possibilita a } \\
\text { aprendizagem de forma assíncrona ou } \\
\text { síncrona; possibilita ao aluno gerir o seu próprio } \\
\text { tempo/local para o estudo (flexibilidade); as } \\
\text { pessoas que participam em um sistema fechado } \\
\text { estão alinhadas num mesmo propósito } \\
\text { (conforme as atividades propostas); possibilita } \\
\text { que muitas pessoas utilizem ao mesmo tempo. }\end{array}$ & $\begin{array}{l}\text { Os materiais disponíveis não são, normalmente, } \\
\text { utilizados abertamente, sendo permitido seu uso } \\
\text { somente durante a duração do curso; depende } \\
\text { de conexão com a internet (velocidade rápida) } \\
\text { para a sua utilização; necessita de disciplina e } \\
\text { organização (gestão do tempo) por parte do } \\
\text { usuário para cumprir as tarefas no prazo } \\
\text { estabelecido. }\end{array}$ \\
\hline
\end{tabular}

Fonte: Alves e Brito, 2005; Salvador e Píton-Gonçalves, 2006; Lopes et al., 2007; Marinho et al., 2008; Paiva, 2010.

seus objetivos pedagógicos. (Machado, 2005; Paiva , 2010). O sucesso do Moodle se deve ao fato de que o sistema teve o seu código disponibilizado para que programadores nas várias partes do mundo contribuíssem com novas aplicações para o programa, e hoje o sistema é mais utilizados nos cursos a distância. O público alvo do Moodle são professores responsáveis pelas áreas de formação/ensino nas empresas, escolas e organizações públicas, equipes de apoio a atividades pedagógicas mediadas por computador, profissionais de $\mathrm{EAD}$, tecnologia educacional e interessados que pretendem utilizar ou experimentar o Moodle para disponibilizar cursos a distância ou para complemento a aulas ou cursos semipresenciais.

A filosofia educacional do Moodle é a do construcionismo, que afirma que o conhecimento é construído na mente do usuário, ao invés de ser transmitido sem mudanças a partir de livros, aulas expositivas ou outros recursos tradicionais de instrução. Deste ponto de vista, os cursos desenvolvidos no Moodle são criados em um ambiente centrado no estudante e não no professor. O professor ajuda o aluno a construir este conhecimento com base nas suas habilidades e conhecimentos próprios, ao invés de simplesmente publicar e transmitir esseconhecimento. Por esta razão, o Moodle dá uma grande ênfase às ferramentas de interação entre os protagonistas e participantes de um curso. A filosofia pedagógica do Moodle também fortalece a noção de que o aprendizado ocorre particularmente em ambientes colaborativos. $\mathrm{Na}$ Tabela 1 são apresentadas uma série de vantagens e desvantagens em relação à plataforma Moodle.

\section{METODOLOGIA}

\section{Características do Curso}

A proposta de Mestrado Profissional em Tecnologia Mineral é oferecida pela Universidade Federal do Pampa (UNIPAMPA), em parceria com a Universidade Federal do Rio Grande dos Sul (UFRGS) e Universidade Federal de Santa Maria (UFSM). Trata-se de uma proposta sob a perspectiva de representar um compromisso, tanto com a comunidade quanto com os meios científicos e acadêmicos ao encontro de uma antiga demanda da região, ou seja, de dispor de um curso de pós-graduação em uma área de conhecimento que sempre representou uma vocação natural do município de Caçapava do Sul e região central do estado do Rio Grande do Sul: a tecnologia mineral. Esse projeto oferece, inicialmente, à comunidade científica e empresarial uma linha de atuação, "Gestão Ambiental e Sustentabilidade na Mineração", com o compromisso de posteriormente oferecer outras linhas de pesquisa, considerando as necessidades da comunidade e do grupo de professores que participam do curso.

$O$ curso caracteriza-se por ser semi-presencial, de modo a otimizar o número de interessados e despertar interesse na participação de profissionais já atuantes no mercado de trabalho. 


\section{Perfil da Clientela}

A escolha de Caçapava do Sul para a implantação do Curso de Mestrado Profissional em Tecnologia Mineral deve-se à existência, no município, de um Curso Superior de Tecnologia em Mineração, e cursos de graduação em Geofísica e Geologia, e neles um grupo de professores doutores (Engenheiros de Minas, Geólogos e Geofísicos), com competência para compor o núcleo docente do curso. Outro aspecto importante é a localização da cidade, em uma região de grande relevância pela sua atividade mineira, sendo ponto de referência para outras instituições de ensino superior do país.

$\mathrm{Na}$ sequência são listadas uma série de empresas e órgãos de fomento que demonstraram interesse na efetivação do mestrado profissionalizante: Prefeitura Municipal de Caçapava do Sul. - Caçapava do Sul (RS); Mining Ventures Brasil Pesquisa e Mineração Ltda. São Paulo
(SP); Mineração Mônego Ltda. - Caçapava do Sul (RS); Sangali \& Cia. Ltda. - Caçapava do Sul (RS); Irmãos Cioccari \& Cia. Ltda. - Caçapava do Sul (RS); Mario Razzera e Cia. Ltda. - Caçapava do Sul (RS); Indústrias de Calcários Caçapava Ltda. - Caçapava do Sul (RS); Dagoberto Barcellos S.A. - Caçapava do Sul (RS); Indústria de Calcário Vigor Ltda. - Caçapava do Sul (RS); Calcário Andreazza Ltda. Vila Nova (RS); Companhia de Pesquisas de Recursos Minerais - CPRM. Porto Alegre (RS); Indústria Carbonífera Rio Deserto Ltda. Criciúma, Santa Catarina (SC); Geodecon Geologia e Geofísica Ltda. - Curitiba (PR); Planageo Serviços e Consultoria Ltda. Santa Maria (RS); Amarilo Mineração do Brasil Ltda. - Belo Horizonte (MG); Coogamai - Cooperativa de Garimpeiros do Médio e Alto Uruguai Ltda. Ametista do Sul (RS) e Prospecsolos Geologia e Sondagens. - Belo Horizonte (MG).

A UNIPAMPA, visando criar um vínculo

Tabela 2. Organograma curricular do PPGTM-UNIPAMPA

\begin{tabular}{|c|c|c|c|}
\hline \multirow{2}{*}{ Componente curricular } & \multirow{2}{*}{ Regime } & \multicolumn{2}{|c|}{ Período de Execução } \\
\hline & & Trimestre & Ano \\
\hline Geodinâmica externa da terra & Obrigt. & $1^{\mathrm{o}}$ & $1^{\circ}$ \\
\hline Caracterização das mineralizações & Obrigt. & $2^{\circ}$ & $1^{\circ}$ \\
\hline Atividades Práticas de Campo & Obrigt. & $3^{\circ}$ & $1^{\circ}$ \\
\hline Tópicos Especiais I e II & Obrigt. & $1^{\circ}$ e $2^{\circ}$ & $2^{\circ}$ \\
\hline $\begin{array}{l}\text { Química do meio ambiente aplicada à } \\
\text { mineração }\end{array}$ & Optat. & $1^{\mathrm{o}}$ & $1^{\circ}$ \\
\hline Ecotoxicologia & Optat. & $1^{\circ}$ & $1^{\circ}$ \\
\hline $\begin{array}{l}\text { Estabilidade dos trabalhos mineiros e mecânica } \\
\text { de solos }\end{array}$ & Optat. & $1^{\circ}$ & $1^{\circ}$ \\
\hline $\begin{array}{l}\text { Métodos Geofísicos aplicados a problemática } \\
\text { ambiental }\end{array}$ & Optat. & $1^{\circ}$ & $1^{\circ}$ \\
\hline Sustentabilidade na mineração & Optat. & $1^{\mathrm{o}}$ & $1^{\mathrm{o}}$ \\
\hline $\begin{array}{l}\text { Metodologia de amostragem para } \\
\text { monitoramento do meio ambiente }\end{array}$ & Optat. & $2^{\circ}$ & $1^{\circ}$ \\
\hline $\begin{array}{l}\text { Avaliação de impactos na mineração e } \\
\text { legislação correlata }\end{array}$ & Optat. & $2^{\circ}$ & $1^{\circ}$ \\
\hline Análise Química e instrumental & Optat. & $2^{\circ}$ & $1^{\circ}$ \\
\hline Geofísica I & Optat. & $2^{\circ}$ & $1^{\circ}$ \\
\hline Geoestatística & Optat. & $2^{\circ}$ & $1^{\circ}$ \\
\hline Controle ambiental da água & Optat. & $3^{\circ}$ & $1^{\circ}$ \\
\hline $\begin{array}{l}\text { Medidas ambientais associadas ao meio } \\
\text { biótico. }\end{array}$ & Optat. & $3^{\circ}$ & $1^{\circ}$ \\
\hline $\begin{array}{l}\text { Implantação de aterros sanitários em cavas de } \\
\text { mineração }\end{array}$ & Optat. & $3^{\circ}$ & $1^{\circ}$ \\
\hline $\begin{array}{l}\text { Impactos associados a ruídos e vibrações na } \\
\text { mineração }\end{array}$ & Optat. & $3^{\circ}$ & $1^{\circ}$ \\
\hline Fechamento e reabilitação de sítios mineiros & Optat. & $3^{\circ}$ & $1^{\circ}$ \\
\hline Geofísica II & Optat. & $3^{\circ}$ & $1^{\circ}$ \\
\hline $\begin{array}{l}\text { Impactos ambientais de usinas de tratamento } \\
\text { de minérios }\end{array}$ & Optat. & $3^{\circ}$ & $1^{\circ}$ \\
\hline Ciclos biogeoquímicos & Optat. & $2^{\circ}$ & $1^{\mathrm{o}}$ \\
\hline
\end{tabular}


importante entre empresa e Universidade, assinou convênios com as empresas mencionadas anteriormente, cujas atividades estão relacionadas com o Curso Superior de Tecnologia em Mineração e, consequentemente, com o Mestrado Profissional proposto.

Portanto, essa sinalização de parceria passa pela formação de recursos humanos desses órgãos e empresas em nível stricto sensu.

\section{Componentes curriculares}

O curso será desenvolvido ao longo de dois anos, com as disciplinas obrigatórias cursadas preferencialmente no primeiro ano (Tabela 2). As disciplinas optativas serão ministradas ao longo dos dois anos. O ano letivo será dividido em 3 (três) trimestres de 12 (doze) semanas de duração cada um. As aulas serão ministradas no início de cada trimestre, quando os discentes receberão materiais didáticos para serem analisados e desenvolvidos extraclasse e também podem ser na forma de seminários apresentados no final de cada trimestre.

Várias ferramentas estão sendo propostas via Plataforma Moodle e serão utilizadas na complementação à distância das disciplinas, como: repositório de arquivos, mensagens, usuários online, calendário, notas, chats, fóruns, glossário, questionário, tarefas e wikis.

\section{RESULTADOS E DISCUSSÃO}

Primeiramente, foi selecionado o material didático a ser disponibilizado no ambiente Moodle, onde a plataforma foi pensada como suporte para disponibilização digital com uma linguagem coloquial dos objetivos, metas e discussões de cada capítulo das disciplinas propostas (Tabela 3 ).

Uma vez selecionado o material didático, o mesmo foi inserido na plataforma (Figuras 1, 2 e 3), onde no período de novembro a dezembro de 2012, os docentes do programa passarão por capacitação sob supervisão do Núcleo de Tecnologias Educacionais da UFSM (NTE/UFSM).

A maior expectativa se refere a utilização da plataforma para realização de atividades e também para o gerenciamento do desempenho dos mestrandos. Como o programa é avaliado anualmente, existe uma cobrança natural por parte da CAPES quanto à necessidade de se obter bons indicadores nas avaliações externas. Com a elaboração desta proposta didática, percebe-se a possibilidade de organizar o tempo das aulas de acordo com as habilidades e competências determinadas pelo programa das disciplinas. Esperam-se naturalmente algumas dificuldades iniciais por parte dos mestrandos, mas nada que a interação virtual não solucione para que a utilização da plataforma funcione como recurso didático. Aspectos como a possibilidade de discussão de problemas, geração de um feedback para os mestrandos, disponibilização de recursos multimídia nas atividades, além da possibilidade de acompanhar as atividades realizadas pelos mestrandos, verificando as dificuldades que os mesmos encontram em cada atividade, destacam a proposta. Além disso, a possibilidade de realizar análises mais detalhadas sobre o desempenho dos mestrandos, de modo a serem criadas novas estratégias para melhorar o desempenho dos mesmos nos

Tabela 3. Disciplinas propostas em ambiente Moodle, com os respectivos programas.

\begin{tabular}{|c|c|c|}
\hline $\begin{array}{c}\text { Ciclos } \\
\text { biogeoquímicos }\end{array}$ & $\begin{array}{l}\text { Fundamentos da } \\
\text { Ecotoxicologia }\end{array}$ & $\begin{array}{c}\text { Controle Ambiental } \\
\text { da Água }\end{array}$ \\
\hline $\begin{array}{l}\text { - Ciclo dos elementos vitais; } \\
\text { - Ciclos gasosos e sedimen- } \\
\text { tares do carbono, enxofre, } \\
\text { nitrogênio e fósforo); } \\
\text { - Química do sistema terrestre; } \\
\text { - Quimica da atmosfera em } \\
\text { fase aquosa; } \\
\text { - Fontes renováveis e não- } \\
\text { renováveis de energia; } \\
\text { - Gestão e planejamento do } \\
\text { ambiente. }\end{array}$ & $\begin{array}{l}\text { - População, recursos naturais } \\
\text { e poluição; } \\
\text { - Ecossistemas } \\
\text { (definição e estrutura, fluxo de } \\
\text { energia, cadeias alimen-tares, } \\
\text { produtividade ecoló-gica, } \\
\text { amplificação bioló-gica, } \\
\text { biomas); } \\
\text { - Intervenção antrópica; } \\
\text { - Ecotoxicocinética; } \\
\text { - Bioacumulação; } \\
\text { - Intoxicação e avaliação da } \\
\text { toxocidade; } \\
\text { - Depuração ambiental. }\end{array}$ & $\begin{array}{l}\text { - A água na natureza; } \\
\text { - Requisitos de qualidade; } \\
\text { - Aspectos legais e institu- } \\
\text { cionais; } \\
\text { - Parâmetros indicadores de } \\
\text { qualidade; } \\
\text { - Reuso da água } \\
\text { - Manutenção da qualidade das } \\
\text { águas naturais. }\end{array}$ \\
\hline
\end{tabular}




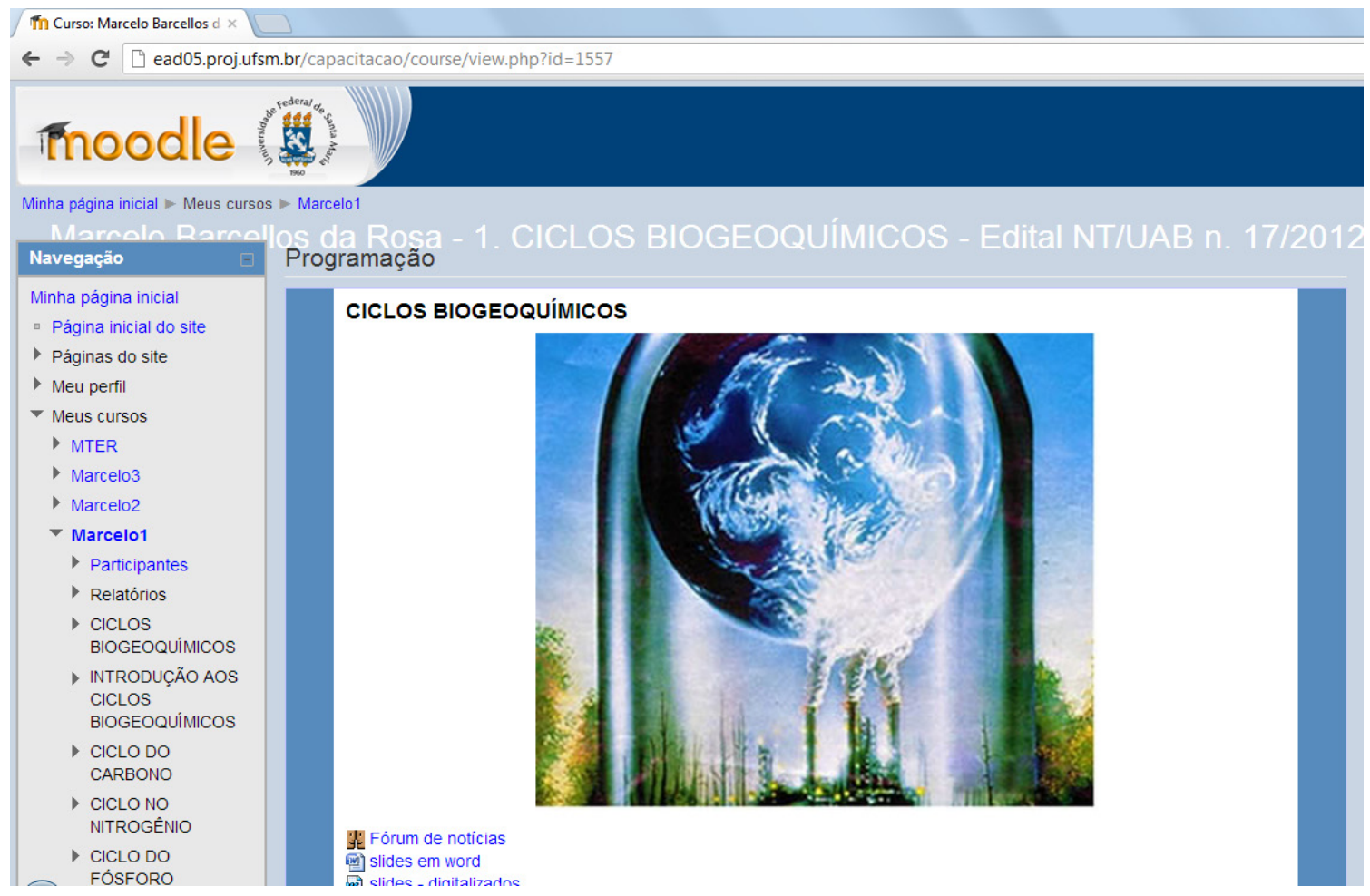

Figura 1. Página inicial da disciplina Ciclos Biogeoquímicos.

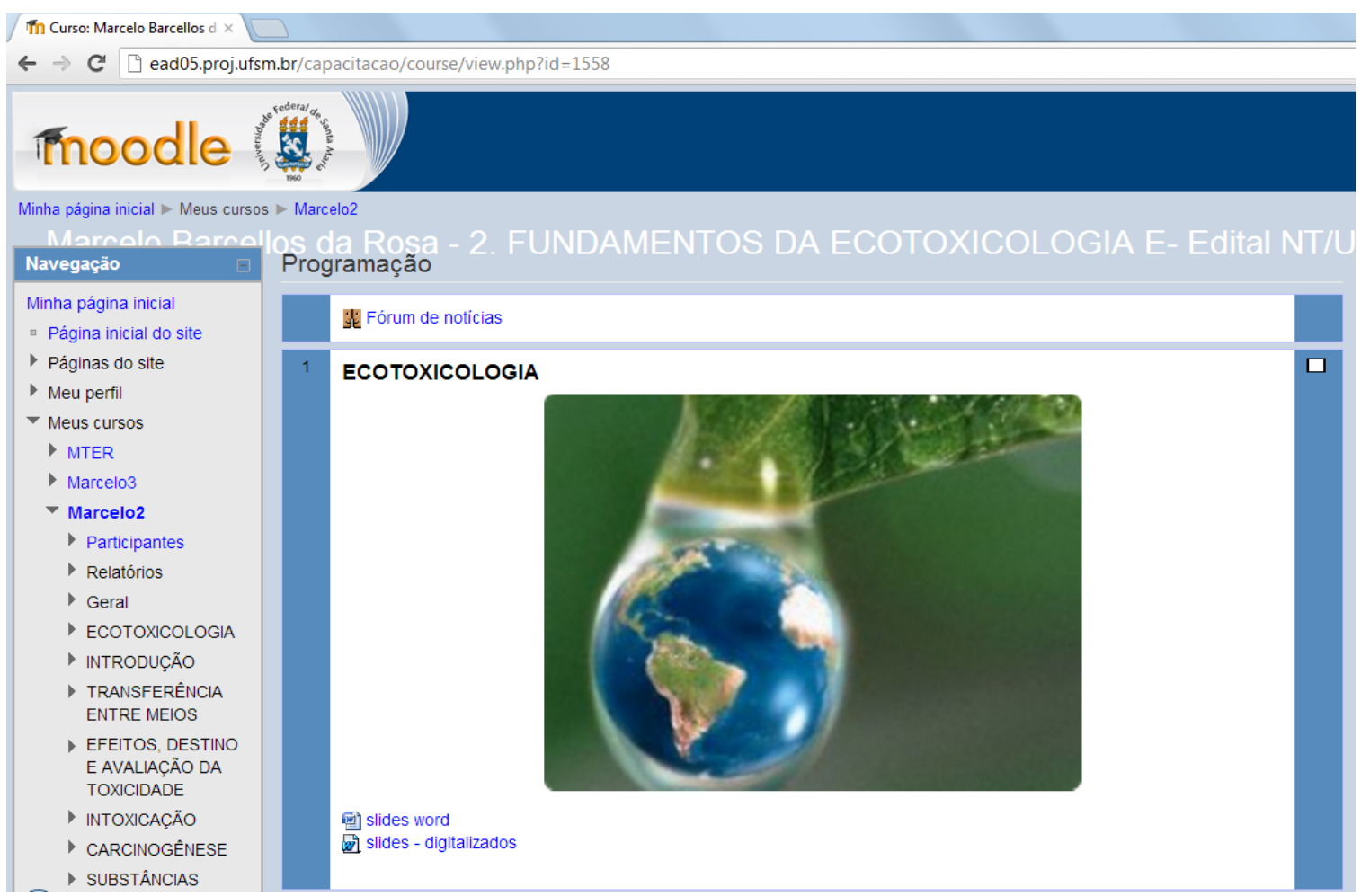

Figura 2. Página inicial da disciplina Fundamentos da Ecotoxicologia 


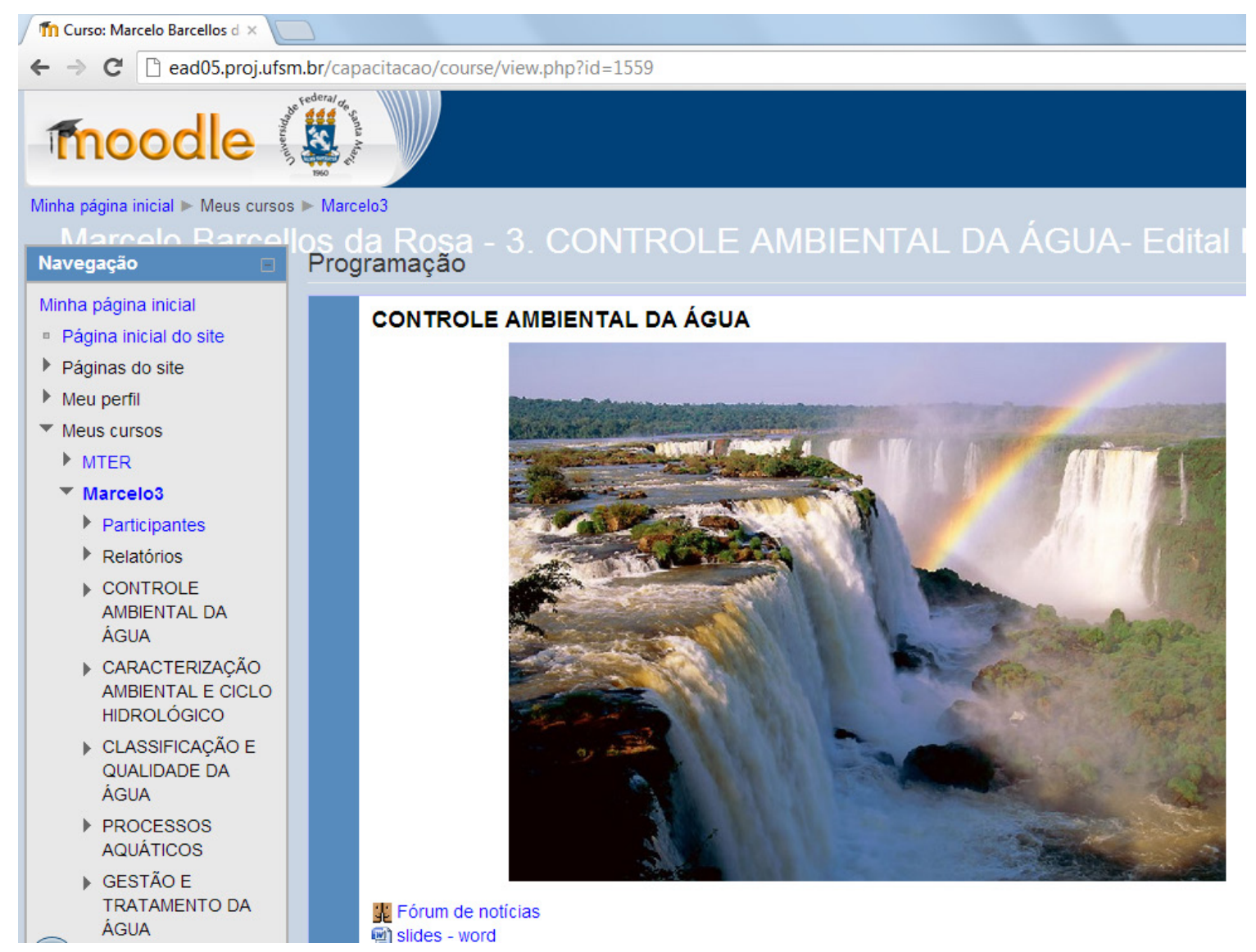

Figura 3. Página inicial da disciplina Controle Ambiental da Água.

indicadores de qualidade criados pelos avaliadores externos, também são observados como aspectos positivos da proposta.

Além da preocupação com as avaliações da CAPES, justificada pelo desejo de consolidação do curso, a criação de uma nova cultura de ensino-aprendizagem é naturalmente fomentada, devido às proposições oferecidas pela plataforma aos mestrando quanto sua autonomia. a plataforma propõe aos mestrandos uma maior autonomia. A possibilidade de disponibilizar aos mestrandos todo o material utilizado nas aulas presenciais para acesso na plataforma com suas senhas pessoais empodera os mestrandos, e dá-lhes mais independência em relação aos professores quanto ao acesso à informação.

Para o professor, um dos grandes desafios é possibilitar que o mestrando desenvolva a capacidade de aprender, e reconhecer seu papel nesse processo e descobrir caminhos e nuances da estrutura de conhecimento formal para tornar-se cada vez mais independente em relação ao professor e ao programa de pós-graduação. Nesse caso, a aula presencial transforma-se em um espaço de debate e construção e deixa de ser simplesmente um local de transferência de informações. Assim, cabe ressaltar que, uma aprendizagem dinâmica, onde se respeita o conhecimento prévio dos mestrandos e sua capacidade de interação e construção de novos saberes, torna naturalmente o pós-graduando mais motivado. Portanto, um dos objetivos fundamentais da proposta, ou seja, uso de novas tecnologias de ensino-aprendizagem em programas stricto sensu, visa instigar o pós-graduando a buscar conhecimento.

Em relação às possíveis dificuldades iniciais, acredita-se que a falta de tempo para utilização da plataforma pode vir a desmotivar os pós-graduandos. Porém, acredita-se que, iniciadas efetivamente as atividades, a realocação de tempo acontecerá naturalmente por parte do pós-graduando.

\section{CONCLUSÕES}

Neste artigo, foram propostas disciplinas a 
partir de um ambiente virtual com vistas a atender o corpo docente e discente do mestrado profissional em Tecnologia Mineral UNIPAMPA. Três disciplinas, Controle Ambiental da Água, Fundamentos da Ecotoxicologia e Ciclos Biogeoquímicos foram criadas para servir de exemplo ao corpo docente do curso e capacitações vem sendo oferecidas aos docentes, na forma de seminários promovidos pelo NTE/UFSM com vistas a elaboração a elaboração e manuseio de todas as disciplinas do curso no ambiente Moodle.

É importante salientar as vantagens do ambiente virtual, que são bem maiores que as possíveis desvantagens, uma vez que apontam possibilidades diversificadas de ampliação do universo de ensino-aprendizagem, onde o principal foco é o saber a partir do desenvolvimento individual e singular do próprio indivíduo. O professor, neste contexto, será um guia, um facilitador, onde, através da comunicação interpessoal, servirá como uma ponte entre o acadêmico e o conhecimento. Muito mais do que a aprendizagem de um certo conteúdo, está em questão aqui a proposta de uma nova forma de adquirir informação e transformá-la em conhecimento, através do uso reflexivo das novas tecnologias e de uma nova dinâmica de aprendizagem conectada ao contexto do sujeito.

Portanto, espera-se que, com o uso de novas tecnologias, como a plataforma Moodle, seja possível tanto consolidar o mestrado profissionalizante em Tecnologia Mineral da UNIPAMPA, quanto sedimentar o uso de novas tecnologias de ensino-aprendizagem em programas de pós-graduação stricto sensu.

\section{REFERÊNCIAS BIBLIOGRÁFICAS}

ALVES, L, BRITO, M. O Ambiente Moodle como Apoio ao Ensino Presencial

Disponível em http://www.abed.org.br/congresso2005/por/pdf/085tcc3.pdf Acessado em $22 / 04 / 2012$.

BARROS, E. C., VALENTIM, M. C., MELO, M. A. A. O debate sobre o mestrado profissional na Capes: trajetória e definições. R B P G, v. 2, n. 4, p. 124-138, jul. 2005.

BELLONI, M.L. Mediatização - os desafios das novas tecnologias de informação e comunicação. In: BELLONI, M.L. Educação a distância. Editora Autores Associados, 1999, pp. 53-77.
CAPES. Portaria $\mathrm{n}^{\circ} 80$ de 16 de dezembro de 1998. Dispõe sobre o reconhecimento dos mestrados profissionais e dá outras providências. Diário Oficial da União, Seção I, p. 14 de 11 de janeiro de 1999.

HAGUENAUER, C. J. ; LOPEZ, F. B.; MARTINS, F. N.; BARBOSA, M. V. G.. Estudo Comparativo de Sistemas de Gerenciamento da Aprendizagem Online. Revista Educaonline, Vol 1, $\mathrm{n}^{\circ} 3$, setembro/ dezembro de 2007.

Levy, P. As tecnologias da inteligência: o futuro do pensamento na era da informática. Tradução de: Carlos I. da Costa. Rio de Janeiro: Ed. 34, 1997.

LOPES, A. M. A.; SILVA, S.V.; BOECHAT, J.; OLIVEIRA, S. S.; ALVES, P. M. Reforço ao Ensino Presencial Através do Ambiente Moodle - uma Abordagem Baseada no Curso de Engenharia de Produção dos Institutos Superiores de Educação do CENSA (ISECENSA). XXVII Encontro Nacional de Engenharia de Produção (ENEGEP), Foz do Iguaçu, 2007.

LOPEZ, J. M.; ROMERO, E.; ROPERO, E. Utilización de Moodle para el desarrollo y evaluación de competencias en los Alumnos. Form. Univ., La Serena, v. 3, n. 3, 2010.

MACHADO, C. B. A Geografia na sala de aula: Informática. Sensoriamento Remoto e Sistemas de Informações Geográficas - recursos didáticos para o estudo do espaço geográfico. Anais XII Simpósio Brasileiro de Sensoriamento Remoto, Goiânia, Brasil, 16-21 abril 2005, INPE, p. 1297-1304.

MARINHO, F.C.V.; VIEIRA, E. R.; MEIRELLES, R. M. C. \& CUNHA, J. L. Avaliações on-line: quebrando paradigmas. VI Seminário de Pesquisa em Educação Matemática do Estado do Rio de Janeiro. Rio de Janeiro, 2008.

PAIVA, V. M. O. Ambientes virtuais de aprendizagem: implicações epistemológicas. Educ. rev., Belo Horizonte, v. 26, n. 3, Dec. 2010.

PRIMO, A. Ferramentas de interação em ambientes educacionais mediados por computador. Educação, v.XXIV, n. 44, p. 127-149, 2001.

RIBEIRO, R. J. Ainda sobre o Mestrado Profissional. R B P G, Brasília, v. 3, n. 6, p. 313-315, dez. 2006.

SALVADOR, J. A. \& PITON-GONÇALVES, J. 
O MOODLE como ferramenta de apoio a uma disciplina presencial de ciências exatas. In. Anais do XXXIV COBENGE - Congresso Brasileiro de Ensino de Engenharia, Passo Fundo, 2006.

SILVA JUNIOR, João dos Reis. Reformas do estado e da educação e as políticas públicas para a formação de professores a distância: implicações políticas e teóricas. In: Revista Brasileira de Educação -

ANPED. Rio de Janeiro, Set/dez 2003, p. 78-94.

SILVA, Marcos. Sala de aula interativa. São Paulo: Loyola, 2003.

SILVEIRA, V. O.; PINTO, F. C. S. Reflexões necessárias sobre o mestrado profissional. R B P G, v. 2, n. 4, p. 38-47, jul. 2005. 